\title{
Psychology of color, integration of local culture and effect of infographics on English language learning
}

\author{
Intakhab Alam Khan \\ King Abdulaziz University, Jeddah, Saudi Arabia
}

Infographics

on English language teaching

Received 19 February 2021 Revised 19 May 2021 Accepted 13 August 2021

\begin{abstract}
Purpose-Many students are found facing difficulties in learning English due to plenty of reasons: known and unknown ones. In order to overcome such an issue, the instructors have to explore for effective techniques of teaching English to motivate learners by any means. Technology in general and informatics in particular can be thought of as innovative tool of pedagogy in the current teaching-learning environment. The present proposal of research aims at creating innovative approaches, which attract learners' interest and catch their attention for better outputs.

Design/methodology/approach - Following subsections have been discussed keeping the significance in view. Setting of the study: The present study was conducted at King Abdulaziz University, Jeddah-Saudi Arabia, which is one of the Saudi Arabian universities; however, it has opened up new avenues for the pedagogues, teachers of English and researchers to conduct studies in various allied fields. In order to have a representative sample of students' population, the participants were chosen from the "preparatory year". Material and tools: This study used a questionnaire (Appendix) and a test to evaluate performances of the two groups: controlled and experimental. In order to further strengthen the findings, semi structured interview was conducted for a few select students from the student-sample. Since the questionnaire was adapted, the statistical validity and reliability was not considered to be essential; however, content/face validity was ensured by consulting 10 experts in the field of education/methods of teaching.

Findings - Based on the analysis of data gathered from the test performances of the two groups of students, it was found that there existed a significant difference in the test scores. The questionnaire responses also proved that infographics can be proved to be an interesting tool of education in general and English language teaching in particular. However, it has been noticed from the gathered data that not many teachers are comfortable using multimedia or infographics for different reasons. The results of the present study are in line with the study by Rezaei and Sayadian (2015) that support the idea of infographics that would help English teachers to develop understanding and insights to design among the learners. They further contend that the infographic instruction offers choices for the utilization of collaborative activities. In addition, the infographics enhance students' performance as a whole as also supported by Alrwele (2017).

Research limitations/implications - The study was conducted on a small sample which might affect the generalization of the outcomes. It was carried out with special reference to teaching of vocabulary and reading. Practical implications - There can be many recommendations for different stakeholders. For teachers, it is recommended that they should know about the significance of infographs for catching the attention of students. They should know how to design interesting and colorful infographs. The administration/ management should facilitate the teachers with the required software or platform to create infographics and integrate in an English language class. In addition, teachers should attend workshops and training courses organized for topics related to the infographs.
\end{abstract}

\footnotetext{
(C) Intakhab Alam Khan. Published in PSU Research Review. Published by Emerald Publishing Limited. This article is published under the Creative Commons Attribution (CC BY 4.0) licence. Anyone may reproduce, distribute, translate and create derivative works of this article (for both commercial and noncommercial purposes), subject to full attribution to the original publication and authors. The full terms of this licence may be seen at http://creativecommons.org/licences/by/4.0/legalcode

This project was funded by the Deanship of Scientific Research (DSR) at King Abdulaziz University, Jeddah, under grant no. (G: 393-156-1440). The authors, therefore, acknowledge with thanks DSR for technical and financial support.
}

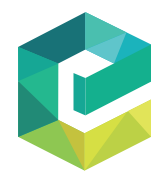

PSU Research Review Emerald Publishing Limited DOI 10.1108/PRR-02-2021-0013 
Originality/value - The author checked the study for plagiarism (excluding references) and found it to be 93\% plagiarism free.

Keywords Psychology, Cognitive development, Technology, EFL learning, Infographics, Local culture

Paper type Research paper

\section{Introduction}

Learning does not take place in isolation. The entire process involves many sub-processes and multiple activities. In addition, an appropriate learning environment is also essential to impart knowledge and facilitate learning. Appropriate leaning environment for a modern classroom has become a necessary condition for effective pedagogy. Much has been researched and explored regarding the utilization of computers, mobiles, web resources, online platforms and so on. However, the effect of use of infographics in an English classroom is the focus of the paper. It is true that all the teachers are not well equipped in designing infographs in a given context. It was mentioned by Fadzil (2018), some of the pre-service teachers were in agreement that infograph creation was quite challenging as they were required to electronically explore the infographic-maker first. Then they were required to master the skills of using the infographic maker, in order to create their own infographics. In addition, online free access of creating or using infographs is also not granted by many platforms or tool developers. However, teachers may use readymade materials, adapt them or use for teaching purposes if there is no copyright issue regarding the download and use. On the other hand, the institution can buy some tools and programs to make teaching-learning effective provided the purchase is reasonable.

From a pedagogical point of view, technology integration is more beneficial than mere traditional teaching methods. Formal classroom interactions are not the only means of learning. Nowadays, aspirants can learn from anywhere and at anytime with the help of a machine and Internet connection. Online/e-learning mode of learning and education may be friendlier for an innovative learner than facing heavy traffic while going to schools and sweating for hours. In most of the technologically equipped educational institutions in Saudi Arabia, the technology integration or blended learning into tertiary level classrooms have passed through significant changes in recent years (Khan, 2014). Language labs and computer assisted learning modes are quite frequently used for teaching/learning of a foreign language (English) in most modern and digital setting.

\section{The concept and relevance of infographics}

An "infographic" or information graphic as defined by the Oxford Dictionary is nothing but "a visual representation of information or data". However, the meaning may differ in specific situation.

Infographics are made from graphic information or data aiming to show complex information in a better manner (Newsom and Haynes, 2004). In this connection, Heer et al. (2010) called infographics as architecture of information. Infographic was initially used in 1,626 by Christopher Scheiner in a book, and the term "Infographic" was coined by Sullivan in 1970 (both cited in Bicen and Beheshti, 2017). Sylvester used this concept in Algebraical theory in 1858. The ultimate purpose of infographic can include informing, entertain and persuading the audience (Krum, 2014).

\section{Utilization of infographics in education}

The concept of "infographics" includes a story, process and idea. Hence, it must be kept in mind that any subject can be designed by infographics by means of applying appropriate visual presentation (Lamb and Johnson, 2014). Most instructors or pedagogues basically design infographics to clarify complex information in a precise and vivid manner. This feature enables instructors to catch attention of the target learners as a warm up activity or 
pre-reading stage. In addition, the image of infographics systematically summarize for better and faster interaction (Vanichvasin, 2013).

In the book "The power of the Infographics", the author stated that infographics reinforce comprehension by means of distinct digital channels (Smiciklas, 2012). Çifçi1(2016) explored the pedagogic relevance of infographics in geography classrooms. In addition, infographics can be used in a classroom to carry out face to face discussions or via online (MacQuarrie, 2012). Additionally, it has been noted that the visual impact of infographics has the ability to increase the level of participation, interaction and comprehension (MacQuarrie, 2012; Smiciklas, 2012).

\section{Language, culture and EFL teaching}

Language is preserved in cultures, and culture is depicted mainly through languages. The existing relationship between language, thought and linguistic development has already been explored and discussed initially by Chomsky (1975) and later by many others including Bowerman and Levinson (2001). Vygotsky (1978, p. 85) explained how a learner develops cognition based on two stages of development: "the actual development" and the "zone proximal development" (ZPD). The process of maturation is attributed to the ZPD or in other words, we may put that development is immature. On the other hand, "the actual developmental level" refers to a child's capability of accomplishing a task, however, independently.

Culture and language are complimentary to each other. Language learning takes place in socio-cultural context. It has been contended that the target students cannot attain proficiency without a good understanding of cultural perspectives (NSFP, 1996, cited in Peterson and Coltrane, 2003). Byram (1989) studied about how adult learners perceived the use of L1 in target language (L2). In addition, Kramsch (2001) has clearly talked about a logical bond between culture and language.

\section{Learning theory, technology and English language teaching}

Among others, theory of "Behaviourism" focuses only on those aspects of learning that can be objectively observable and observed. Cognitive theories concern "beyond behavior phenomenon" and conclude that learning is initially "brain-based" while the supporters of the theory of "constructivism" conceive that learning is a process in which the learner develops novel and creative ideas.

The cognitive learning theory emphasizes understanding about the "thought processes" and the way the mind can process and store data and information. Most psychologists are of the opinion that behaviorism focused too much on stimuli. They tend to believe that human actions are usually in accordance with the thoughts. Vygotsky's (1978) has talked about the fact that learning is shaped by social influence. In other words, socio-cultural factors are quite significant in the entire process of development. According to the scientist, one's language development is the result of one's culture.

Piaget's theory (1970) focuses on cognitive development that starts when a child (from 12 years) thinks about possibilities and abstractions. Piaget (1985) continued that learning process includes shaping of new information and fitting with the learner's existing knowledge. Key concepts in the cognition include: 1-assimilation (a process in which new objects/events are perceived in terms of existing schemes or operations), 2-accommodation (a next level process in which modification takes place: change in the existing cognitive structures depending upon new information) and 3-equilibration (the final level of development which covers both the process of assimilation and accommodation).

Considering the theoretical aspects as mentioned above in Piaget's theories, infographics can be proved to be quite effective in the process of cognitive development: be it is "Assimilation", “Accommodation" or "Equilibration”. In other words, infographics may help the learner to finally learn and use vocabulary in better manner.
Infographics on English language teaching 
Technology has become so important that currently most of the foreign language books contain course materials with an integrated $\mathrm{CD}$. The integration of technology into language teaching/learning is often known to be quite similar to the concept of computer assisted language learning (CALL). Motteram (2013) states that the diversification of CALL has meant different ways of adapting it to the different areas of English language learning as a whole, e.g. English for special purposes.

Wantulok (2015) lists several reasons why technology is so crucial to education: it's in demand, students can learn at their own pace; it enhances teacher-student and studentstudent relationships; online testing; e-resources and technology is interactive. Herold (2016) states that in public schools in the USA today there is at least one computer available for every five students. The government's expense on digital content is around three billion dollars per year. The whole enterprise of distance education and distance learning offered by colleges and universities worldwide is built on the edifice of technology. Terms such as "blended learning", "online teaching/testing", "technology integration" and "virtual classrooms" have been utilized by most modern scholars and researchers.

Most universities and colleges in Saudi Arabia have fully equipped language classrooms and laboratories. The software programs that are normally installed in the computers contain interactive material that supports student self-study practice of the various skills (reading, writing, speaking and listening). An example of such English language software is "Rosetta Stone". The "Blackboard" is an online platform used by King Abdulaziz University, Jeddah-Kingdom of Saudi Arabia (KSA).

\section{English language teaching: cultural perspective}

Culture based teaching of a foreign language has always been in the focus for a long time, but local cultural integration is of a new origin, and researchers have started exploring its impact on the learning outcomes. If a teacher integrates both local culture and appropriate simple technology the teaching-learning is likely to become more effective.

Infographics can be one such practice of this kind considering its cost-benefit issue and the overall outcome. It does not require lots of preparedness or resources to create and integrate. It is very simple and effective. For example, following image can develop cognition more effectively than traditional teaching, explaining for a long time and yielding fewer outcomes than expected. In other words, Infographic image can be created as shown below to develop cognition among target learners via local cultural connection (see Figures 1-3).

\section{Teaching of English vocabulary}

Vocabulary is the basic building block in language acquisition. Without an adequate foundation in word familiarity, recognition and understanding it will be extremely difficult for a learner to communicate with anyone in the target language. Much has been written about the different methods of teaching vocabulary (AlQahtani, 2015). Some of the techniques theorists and practitioners mention are: use of real objects and models, use of pictures/ diagrams, dictionaries, collocations, idioms, word maps, prefixes/suffixes, teaching words in context, etymology, word associations or word families, homonyms, word cards and the list goes on.

However, it is certain that integration of simple Infographics can enrich teaching-learning of vocabulary of foreign language as it brings the learner closer to the objects thus leading to learning.

Similarly, teachers can create infographics and present a wholesome of concept through appropriate images and related text to teach English effectively to those students whose exposure to the language is quite limited. Following image is the infographics which represent hospital related terms and concepts. 




Infographics

on English language teaching

Figure 1. A sample of infographics used in the study

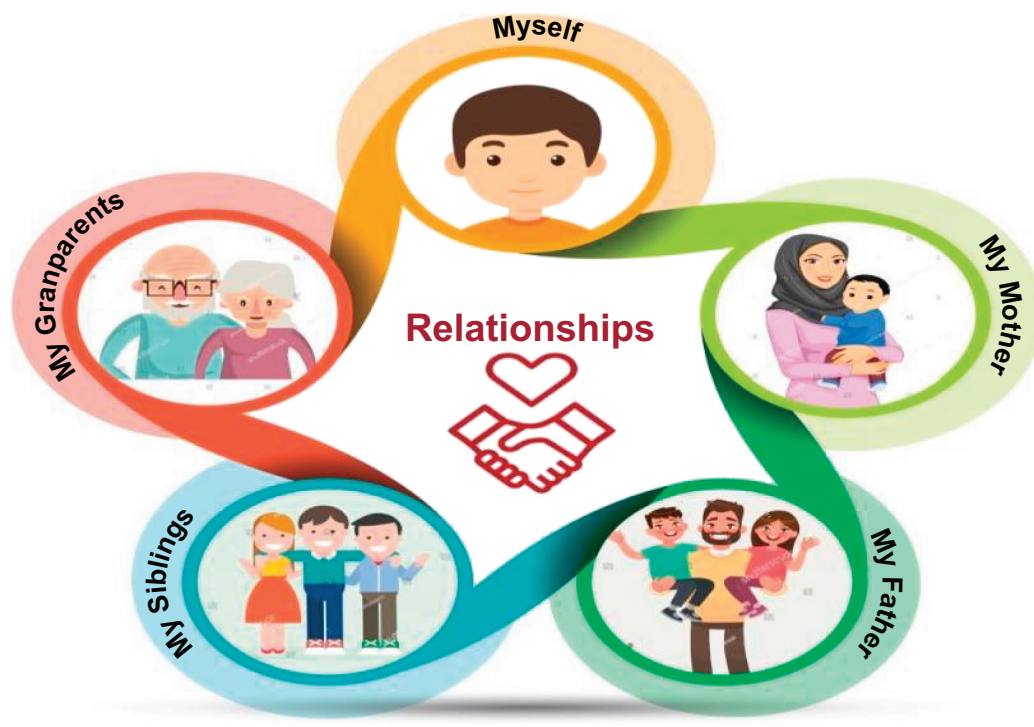

Figure 2. Infographics designed to teach vocabulary

\section{Literature review}

This part is divided into three subsections; however, all are related to research studies conducted in English language teaching perspectives of Saudi Arabia. They are technology integration, critical thinking, culture/local culture and technology.

Research on technology integration

In support of technology use, Haugland and Wright (1997) defended that the "technology" must be compatible and its use should be proper and effective. Therefore, the concerned teachers have 


\section{PRR}

\section{Hospital words}



Figure 3.

Hospital related infographics designed and used in the study to bother more about "how" than "what" and "why" factors. A close connection between early literacy and technology was studied by Labbo et al. (2000) who offered a model for classrooms. The scientists and pedagogues started taking interest in the impact of computers on education in the recent past (Leu, 2002). Some researchers have found positive learning outcomes resulting from technology and online learning, others have not (Chowdhry et al., 2014; Harris et al., 2016; Mc Knight et al., 2016; Olsen and Chernobilsky, 2016). Many academics and parents are of the opinion that "digital distractions" impede the learning process. Herold (2016) refers to research findings that there are some countries where fifteen-year old students used computers excessively in the classroom, but they obtained the worst results on some tests.

\section{Critical thinking, cognition and foreign language learning}

Critical thinking can't be separated completely from the process of cognition, and learning without cognition is seldom possible. Therefore, it is better to review a few studies in this area to connect two concepts together and lead to an overview. Bloom's (1956) taxonomy's main focus was on the process of critical thinking as felt by Duron et al. (2006); however, the idea received attention due to the concept of cognitive development and its levels. Warren et al. (2004) felt that the improvement in the critical thinking skills may take place if these are well integrated into the textbooks and classroom activities. In other words, critical thinking can't be developed in isolation. In addition, Black (2005) claims that students will be able to develop critical skills more easily if the concerned teachers know how to inculcate the ability to think critically by applying reasoning and cognitive abilities. Critical thinking is part of higher thinking order and it belongs to the second level (Duron et al., 2006; Savich, 2008). This is why it is mostly included in the process of learning especially at tertiary level of education.

Savich (2008) also found that students of history developed critical skills more when they were forced and reinforced to. In this connection, Cotter and Tally (2009) point out that even students at the college level are sometimes unable to truly develop the required level of abstract deductive thinking skills as a part of critical thinking. Besides, Choy and Cheah (2009, 
p. 198) also emphasize that despite each normal student has the inborn ability to think critically, the crucial role of teachers' expertise is not over. It is the teacher who would facilitate the learner to reach to the required level of critical thinking (if he is able to). Cotter and Tally (2009) examined critically if working on routine textbook exercises are pretty enough to develop the critical skills. Rezaei and Sayadian (2015) explored the impact of infographics instruction on Iranian EFL learners' grammar learning and found useful. Multi-media in general and infographics in particular can assist the learners to develop critical thinking better than the routine and traditional teaching because these are systematic graphical representations of information and data conducive for critical thinking and cognition.

In sum, infographics can connect the learners through local culture and technology to attain learning goals of a language including cognition which has been conceived by (O'Brien, 2017) as the unique human ability to think. It includes sub abilities like understanding, processing and finally producing novel and sometimes complex ideas or thoughts. The process of "cognition" can further be divided into memory, attention and reasoning.

\section{Culture integration for English language teaching}

Local culture can be a useful resource in an EFL (English as a foreign language) classroom. It will de-burden the target learners by giving them the opportunity to learn the foreign language only and not foreign culture. A country like Saudi Arabia which is culturally rich may not get its learners of English to remain in dilemma to learn an international language or British culture or both. It will be far better if local culture is integrated via technology to teach certain vocabulary and enhance reading skills.

Khan (2014) studied teachers' perceptions on the relevance of local culture which was found quite interesting. Most of the students found it interesting to learn English through familiar topics and subjects. Going bit farther, Khan (2016b) in yet other research, explored the feasibility of different technologies for teaching of the writing skill in English. In addition, Khan (2016a) studies the relevance of Arabic culture in an English classroom and appropriate means to integrate the local culture. The study also explores concerned teachers' preparedness for technology and local culture integration.

Khan (2011) pointed out again that language and culture can't easily be separated; however, to many people, it is not ideal to integrate a foreign language with a local culture. Hence, the idea is useful that has been tried out by many countries where English is used as a second language and even as lingua franca (like in India). In one of his book chapters, Khan (2018) dealt with in detail the issues of integration of local culture for the teaching of English through technology.

\section{Concluding remarks}

Related literature reviews might appear scattered; hence, all types are quite closely related to each other. In a nutshell, English language learning is a complex process which does not only include memorizing a few words and forgetting a specific span of time. It does not also focus on superficial knowledge or low level of comprehension. It rather aims to develop understanding, critical thinking, cognition (all the level as referred by Piaget, 1970). Learning could positively be enforced by the environment (local culture) and digital ecology (technology integration/ blended learning). Studies have been conducted in general in the area of technology integration in general and infographics in particular yet the integration of local cultural and infographics together in teaching-learning in the Saudi context is a study in demand.

\section{The present study}

\section{Statement of the problem}

Many students are found facing difficulties in learning English due to plenty of reasons: known and unknown ones (Khan, 2011, 2016c). In order to overcome such an issue, the
Infographics on English language teaching

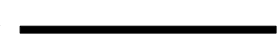


instructors have to explore for effective techniques of teaching English to motivate learners by any means. Technology in general and informatics in particular can be thought of as innovative tool of pedagogy in the current teaching-learning environment. The present proposal of research aims at creating of innovative approaches which attract learners' interest and catch their attention for better outputs.

\section{Objectives}

(1) To elicit the perceptions of English language teachers on the relevance of Multimedia in general and infographics in particular,

(2) To study the relevance of local culture and its integration through technology/ infographics in English language classrooms,

(3) To explore the possible effect of infographics on learning of English in general and vocabulary and reading in particular.

\section{Research questions}

$R Q 1$. What is the significance of infographics in teaching-learning English (with special reference to vocabulary and reading) in KSA?

$R Q 2$. What is the use of infographics on the students' scores?

$R Q 3$. What kinds of infographics and pedagogic intervention are more useful for the teaching-learning of vocabulary and reading in English?

\section{Methodology}

Following subsections have been discussed keeping the significance in view.

\section{Setting of the study}

The present study was conducted at King Abdulaziz University, Jeddah-Saudi Arabia. It is one of the Saudi Arabian universities; however, it has opened up new avenues for the pedagogues, teachers of English and researchers to conduct studies in various allied fields. In order to have a representative sample of students' population, the participants were chosen from the "preparatory year".

\section{Material and tools}

This study used a questionnaire (Appendix) and a test to evaluate performances of the two groups: controlled and experimental. In order to further strengthen the findings, semi structured interview was conducted for a few select students from the student-sample.

Since the questionnaire was adapted, the statistical validity and reliability was not considered to be essential; however, content/face validity was ensured by consulting 10 experts in the field of education/methods of teaching.

\section{Participants}

The sample of the study consisted of 49 male Saudi foundation year students (2 groups: $23+26$ ) whose mother-tongue is naturally Arabic. They were enrolled in the foundation year of KAU University, Jeddah-Saudi Arabia. In the foundation year academic program English is one of the subjects undertaken to facilitate the target learners to acquire proficiency in order to finally prepare them for further studies in the university educational system. 
Data collection

Initially, a test (designed by the testing and evaluation unit for all the enrolled students) was administered to find out difficulties; later strategy will be developed by consulting experts in the field of technology integration. In addition, questionnaires were developed and administered for teachers to elicit the significant of informatics and teachers preparedness for using informatics.

\section{The experiment}

The teacher-researcher taught two groups of students by two different methods: (1) normal way with available material, (2) by integration of local culture and technology especially infographics.

\section{Analysis of data}

Difference between the results of the two sample groups

Achievements (results) of two groups of students (experimental and controlled) were compared. The findings were as under

The mean value of controlled group is 3.51 , whereas the mean value of experimental group is 4.33 , which shows that there is a difference in mean values (see Tables 1-4).

\section{Questionnaire analysis}

This table presents an overall picture of the data in three scales. The raw data have been presented in percentage also for all three categories of the responses. This will be used for descriptive analysis of the questionnaire.

\begin{tabular}{lccccr}
\hline Groups & Mean & $N$ & Std. Deviation & Std. Error mean & Table 1. \\
Controlled & 3.51 & 23 & 2.037 & 0.494 & Statistics of two groups \\
Experimental & 4.33 & 26 & 2.210 & 0.535 & compared \\
\hline
\end{tabular}

\begin{tabular}{lcccr}
\hline Groups & $N$ & Correlation & Sig & $\begin{array}{r}\text { Table 2. } \\
\text { Controlled }\end{array}$ Experimental $^{23}$ \\
26 & 0.973 & 0.000 & $\begin{array}{r}\text { Correlations between } \\
\text { the groups }\end{array}$ \\
\hline
\end{tabular}

Data

\begin{tabular}{|c|c|c|c|c|c|c|c|c|}
\hline \multirow[b]{2}{*}{ Groups } & \multirow[b]{2}{*}{ Mean } & \multirow{2}{*}{$\begin{array}{c}\text { Std. } \\
\text { Deviation }\end{array}$} & \multirow{2}{*}{$\begin{array}{l}\text { Std. Error } \\
\text { mean }\end{array}$} & \multicolumn{2}{|c|}{$\begin{array}{l}95 \% \text { confidence } \\
\text { Interval of the } \\
\text { difference }\end{array}$} & \multirow[b]{2}{*}{$T$} & \multirow[b]{2}{*}{ df } & \multirow{2}{*}{$\begin{array}{c}\text { Sig. } \\
\text { (2-Tailed) }\end{array}$} \\
\hline & & & & Lower & Upper & & & \\
\hline Controlled and & -0.825 & 0.528 & 0.129 & -1.096 & -0.553 & -6.425 & 16 & 0.000 \\
\hline
\end{tabular}
experimental

Note(s): $p$ value $=0.000$ that means there is a significant difference between the controlled and experimental Difference between the groups 


\begin{tabular}{|c|c|c|c|c|c|}
\hline \multirow{9}{*}{ PRR } & \\
\hline & $\mathrm{SN}$ & Statement: $1-15$ & Agree (\%) & Undecided $(\%)$ & Disagree $(\%)$ \\
\hline & 1 & & $24(60)$ & $12(30)$ & $4(10)$ \\
\hline & 2 & & $23(67.4)$ & 7 (17.5) & $10(25)$ \\
\hline & 3 & & $29(72.5)$ & $8(20)$ & $3(7.5)$ \\
\hline & 4 & & $30(75)$ & $5(12.5)$ & 5 (12.5) \\
\hline & 5 & & $15(37.5)$ & $16(40)$ & 9 (22.5) \\
\hline & 6 & & $26(30)$ & $8(20)$ & $6(15)$ \\
\hline & 7 & & $24(60)$ & $8(20)$ & $8(20)$ \\
\hline & 8 & & $22(55)$ & $11(27.5)$ & 7 (17.5) \\
\hline & 9 & & $26(65)$ & 6 (15) & $8(20)$ \\
\hline & 10 & & $29(72.5)$ & 7 (17.5) & $4(10)$ \\
\hline & 11 & & $18(45)$ & $12(30)$ & $10(25)$ \\
\hline & 12 & & $24(60)$ & $6(15)$ & $10(25)$ \\
\hline Table 4. & 13 & & $23(57.5)$ & $8(20)$ & $9(22.5)$ \\
\hline Over all perception of & 14 & & $25(62.5)$ & $6(15)$ & $9(22.5)$ \\
\hline teachers $(N=40)$ & 15 & & $15(37.5)$ & $9(22.5)$ & $16(40)$ \\
\hline
\end{tabular}

\section{Item wise analysis}

Item-1: Infographics are important tools.

In total, $60 \%$ respondents confirm that infographics are important tools of communication/ teaching while only $10 \%$ have negative responses. Those who respond "undecided" are perhaps unknown to the concept and relevance of infographics. We are well aware that a faculty is equipped with different types of teachers who are from different backgrounds; however, the department always develops them through in service training or professional development programs in order to equip them with new pedagogies and technologies to be updated and ready to face challenges. Despite all, some teachers can't change or more clearly they do not want to change or the changing process is too slow to be effective (see Figures 4 and 5).

Item-2: I like infographics and share on my social media pages.

Around $68 \%$ teachers confirm that they share Infographics in my social media pages. It confirms that they have interest in tools like infographics, and if they are further trained, they can develop some infographics for teaching of English too.

Item-3: I can create simple and instructional infographics if I have software.

In total, $72.5 \%$ respondents are in agreement with the idea that they can create simple and instructional infographics if they have software. There are some free infograph-software programs which can be used for the time being; however, in order to use an official purchased software program, institutions can facilitate its teachers.

Item-4: Infographics can be helpful in presenting subjects in an effective and summarized manner.

Teachers (75\%) are of the opinion that Infographics can show the subjects in an effective and summarized form. This can lead to better cognition and learning. Only $12.5 \%$ teachers are either undecided or not in agreement with the statement. Undecided responses may be made due to ignorance of the infographics as a tool of teaching-learning or communication.

Item-5: Infographics motivates students to learn more.

Only $37.5 \%$ teachers could confirm that Infographics motivates students to learn more than the traditional teaching. This can be analyzed as if they ever tried infographics or studies 


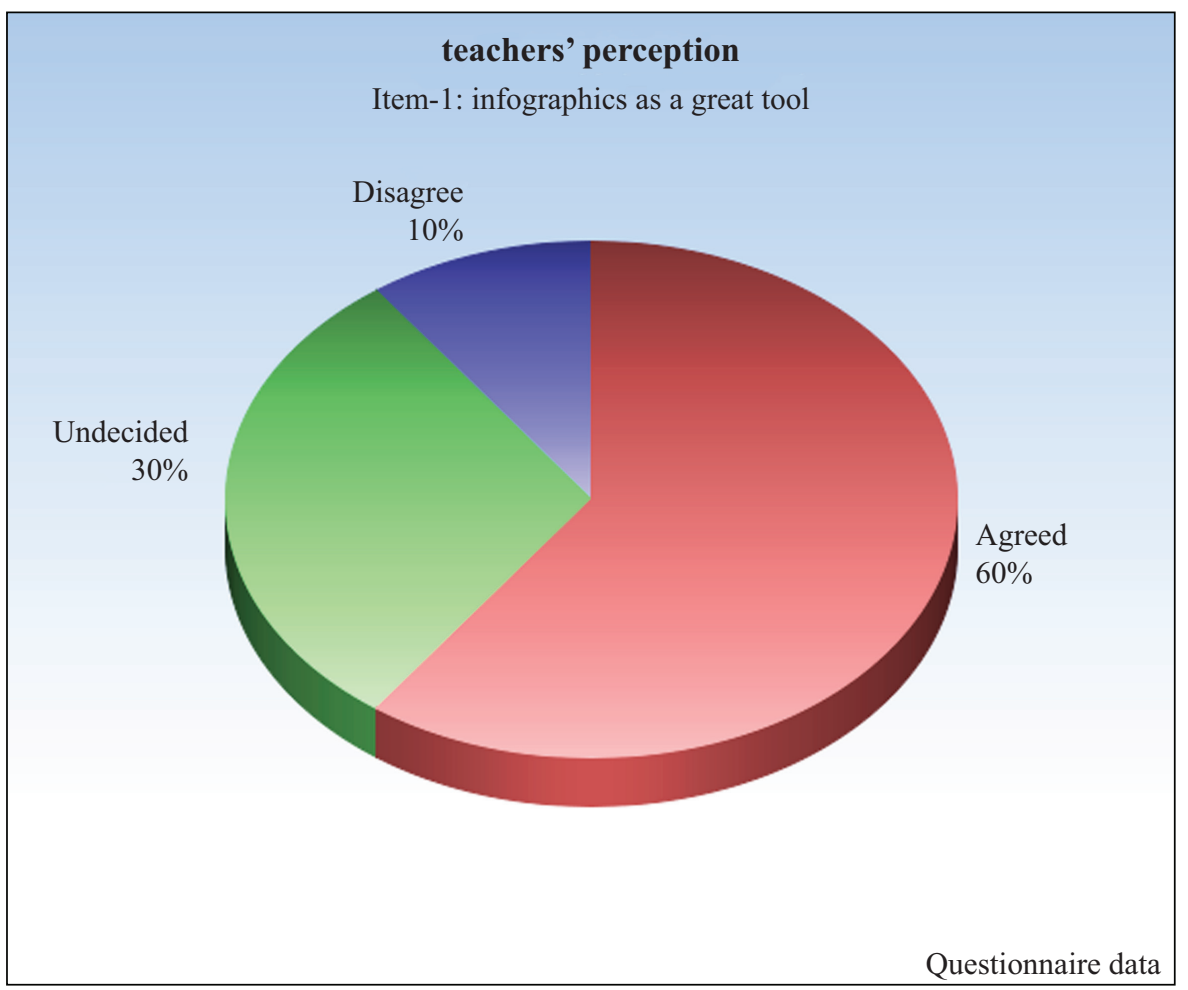

Infographics on English language teaching

Figure 4 . Infographics are great tools

research reports or attended professional development programs in the area of technology integration in general and infographics in particular.

Item-6: If infographics are nicely used in the class, learning will be more effective.

The teachers are not very sure if infographics can be more effective in the EFL classrooms as only $30 \%$ of them responded in agreement of the statement.

Item-7: Infographics can enhance the imagination for cognition.

As $60 \%$ of the teachers agree, it can be analyses that Infographics can enhance the imagination for cognition thus learning can take place in better manner.

Item-8: Infographics can also develop critical thinking and creativity.

According to the $55 \%$ of the teachers' responses, Infographics can be helpful in developing critical thinking and creativity of the EFL learners.

Item-9: Infographics enable the students to learn complex content in easy way.

In total, $65 \%$ of the teachers are in favor of the statement while $15 \%$ respondents are unsure of answer which creates a doubt leading to analysis: do they really know about infographics or they have ever thought of using such tools in their languages classes or do they have any bad experience while making any experiments on infographics.

Item-10: Infographics improve understanding of the subject. 


\section{PRR}

\section{Figure 5.}

Use of "infographs" for cognition enhancement

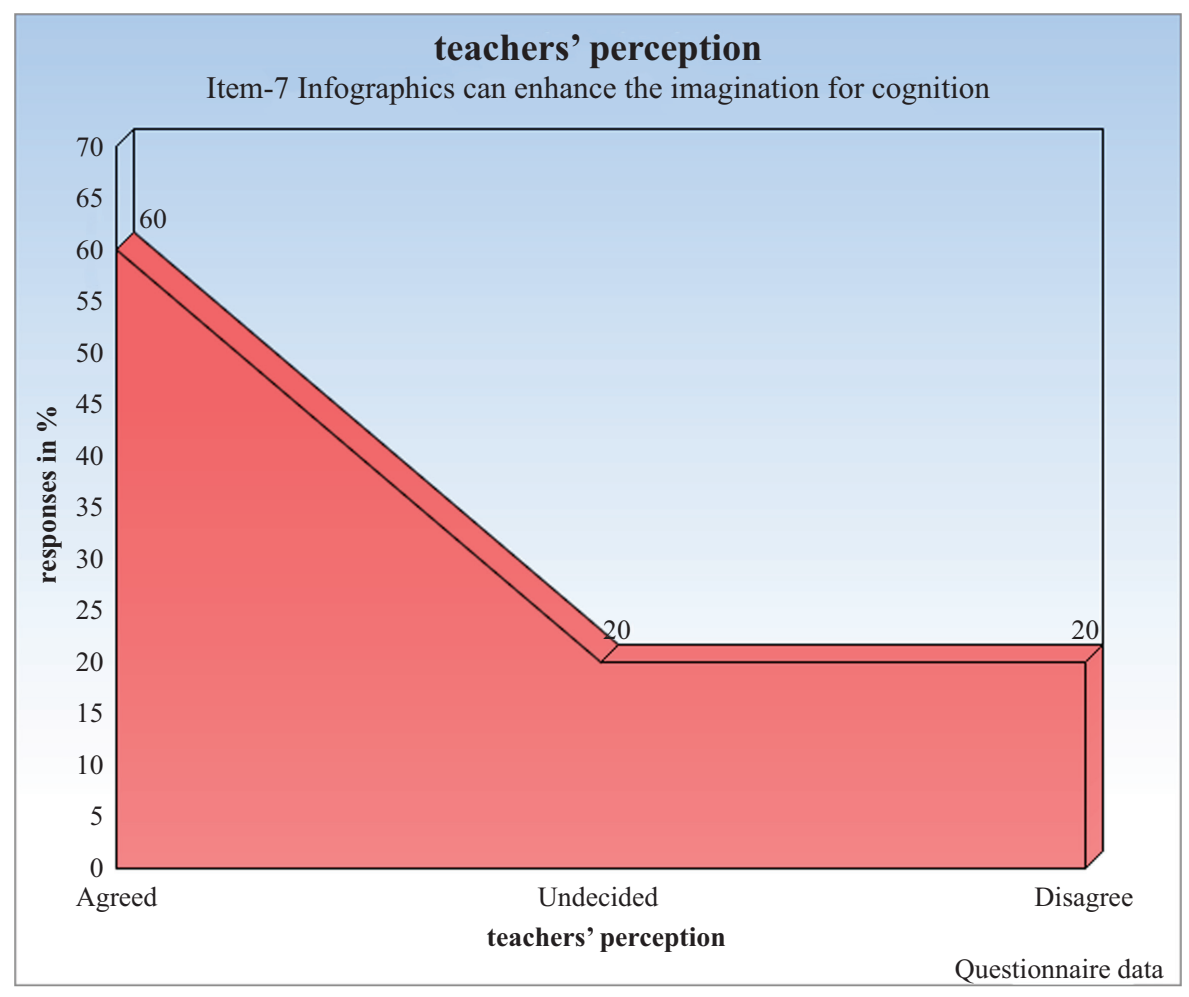

Around $73 \%$ teachers are in agreement with the statement that Infographics are helpful in improvement of the understanding of the subject. Only 10\% respondents disagree while $17.5 \%$ of them are undecided. It can be analyzed that the teachers at least have positive attitude towards utilization of multimedia of infographics in English language classrooms.

Item-11: Infographics enhance communication skills.

Not many are in favor that infographics can enhance communication skills as only $45 \%$ are positive, $25 \%$ disagreed while $30 \%$ undecided. Variations in responses could be due to multiple reasons: due to the difference in cognition and communication process, language learning and communication skills, superficial learning or deep learning and so on.

Item-12: Infographics create visual impact for better learning.

In total, $60 \%$ of the teachers are in agreement with the statement. However, $25 \%$ teachers are negative about it. It is quite likely that the teachers have no idea about connection between infographics and learning-teaching of English. Therefore, they need to be trained in the area of technology integration in general and infographics use in particular.

Item-13: Infographics are effective tools for showing information in systematic ways.

Due the reason that $57 \%$ teachers are in agreement with the statement, it may be concluded that infographics present information systematically which lead to organized teaching and better learning of English.

Item-14: Infographics also create meaningful visual design and tools. 
It has been found that $62.5 \%$ teachers agree that Infographics can be used to utilize creative visual design and technology; however, it remains a questions if they are properly trained or not in the area of technology integration in general and infographics in particular.

Item-15: Infographics are not effective for teaching/learning English

Only $37.5 \%$ teachers responded in positive against a negative statement that means infographics may be a useful tool of teaching English.

\section{Analysis of semi structured interviews}

The semi structured interview questions included key issues taken up in the questionnaire such as:

(1) Students' liking for multimedia and infographics in classrooms,

(2) Usefulness of infographics for learning vocabulary and reading comprehension,

(3) Teachers' preparedness for technology integration,

(4) Need of teacher-training for integration of culture based infographics and so on.

It was found that the students liked the infographics; however, they expressed serious concern over appropriate implementation. They were of the opinion that some teachers were not prepared for technology use as most of them teach following traditional methods of teaching such as lecturing. Like teachers, the students also confirmed that the faculty classrooms are well equipped with technology for sophisticated teaching. Multimedia use in general and infographics in particular could be very interesting, useful and result oriented if employed strategically.

\section{Research questions and results}

Following is a summary of results, in accordance with the research question, mentioned one by one:

(1) Do infographics have any significance in teaching-learning English (with special reference to vocabulary and reading) in KSA?

Analysis of questionnaires, researcher's personal experience and difference between the scores of students in two groups confirm that multimedia and infographs are useful for teaching of English.

(2) Is there any significant effect of use of infographics on the students' scores?

The statistical analysis has shown a significant difference between the achievements of the two groups, thus it is concluded that use of multimedia and infographs yields better results in the learning of English.

(3) What kinds of infographics and pedagogic intervention are more effective for the teaching-learning of vocabulary and reading in English?

It has been found that teaching of English through familiar objects and local environment could be a better experience for many academic and socio-cultural reasons.

\section{Discussion}

Based on the responses and analysis infographics are important tools of teaching. It was also noted that some of the respondents were not certain about some items because they were perhaps unknown to the concept and relevance of infographics. Though some teachers were
Infographics on English language teaching

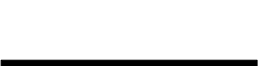


found equipped with infographics and their integration, they were perhaps not much interested in trying technology due to traditional attitude. It was also noted that many teachers utilize infographics in social media or at least they appreciate. It was revealed that the teachers at least have positive attitude towards utilization of multimedia of infographics in English language classrooms. Hence, it is worth mentioning that if they are further trained, they can develop some infographics for teaching of English too. Despite the fact that some free infograph-software program can be accessed, in order to use officially purchased software, institutions can facilitate its teachers, however.

Infographics can show the subjects in an effective and summarized form. This can lead to better cognition and learning. Infographics motivates students to learn more. The study reveals that Infographics motivates students to learn more than the traditional teaching. It was found if infographics are nicely used in the class, learning will be more effective. In addition, Infographics can enhance the imagination for cognition. Thus, learning can take place in better manner. Infographics can be helpful in developing critical thinking and creativity among the EFL learners.

It is quite likely that the teachers have no idea about connection between infographics, visual effect and learning-teaching of English. Therefore, they need to be trained in the area of technology integration in general and infographics use in particular. It may also be concluded that infographics present information systematically which lead to organized teaching and better learning of English. However, proper training and teacher development is imperative.

Based on the interview responses, it was found that the students liked the infographics; however, they expressed serious concern over appropriate implementation. They were of the opinion that some teachers were not prepared for technology use as most of them teach following traditional methods of teaching such as lecturing. Like teachers, the students also confirmed that the faculty classrooms are well equipped with technology for sophisticated teaching. Multimedia use in general and infographics in particular could be very interesting, useful and result oriented if employed strategically.

\section{Conclusions, limitations, recommendations and future research \\ Conclusions}

Based on the analysis of data gathered from the test performances of the two groups of students, it was found that there existed a significant difference in the test scores. The questionnaire responses also proved that infographics can be proved to be an interesting tool of education in general and English language teaching in particular. However, it has been noticed from the gathered data that not many teachers are comfortable using multimedia or infographics for different reasons. The results of the present study are in line with the study by Rezaei and Sayadian (2015) that support the idea of infographics that would help English teachers to develop understanding and insights to design among the learners. They further contend that the infographic instruction offers choices for the utilization of collaborative activities. In addition, the infographics enhance students' performance as a whole as also supported by Alrwele (2017).

It was also found that many teachers are unaware of the tool and they did not receive enough exposure in the area. In this case, there is a need of training or a refresher program for teachers who would use multimedia and infographics in English classroom. Khan (2014) defends the same pedagogic notion. It was also elicited, however, indirectly that readymade tools are missing from the university local platform. Hence, it is important to mention that most of the university's classrooms are highly advanced in the field of technology. Some teachers tend to be unresponsive as far as training in technology integration is concerned. They need intensive training in the field of digital pedagogy. 


\section{Limitations}

The study was conducted on a small sample which might affect the generalization of the outcomes. It was carried out with special reference to teaching of vocabulary and reading.

\section{Recommendations}

There can be many recommendations for different stakeholders. For teachers, it is recommended that they should know about the significance of infographs for catching attention of students. They should know how to design interesting colorful infographs. The administration/management should facilitate the teachers with the required software or platform to create infographics and integrate in an English language class. In addition, teachers should attend workshops and training courses organized for topics related to the infographs.

\section{Future research}

This research opened up new areas of further investigations in related themes. A study may be conducted on a larger sample to ascertain better effect. Similar study can be conducted covering all relevance areas and skills of English language where effect of multi-media and infographics can be seen for better outcomes. To develop better insights, student-population can also be compared within and between colleges/institutes/universities.

\section{References}

Al-Qahtani, M. (2015), "The importance of vocabulary in language learning and how to be taught", International Journal of Teaching and Education, Vol. III No. 3, pp. 21-34.

Alrwele, N. (2017), "Effects of infographics on student achievement and students? Perceptions of the impacts of infographics", Journal of Education and Human Development, Vol. 6 No. 3, pp. 104-117, available at: http://jehdnet.com/journals/jehd/Vol_6_No_3_September_2017/12.pdf.

Bicen, H. and Beheshti, M. (2017), "The psychological impact of infographics in education”, Broad Research in Artificial Intelligence and Neuroscience, Vol. 8 No. 4, pp. 99-108.

Black, S. (2005), "Teaching students to think critically", The Education Digest, Vol. 70 No. 6, pp. $42-47$.

Bowerman, M. and Levinson, S.C. (Eds) (2001), Language Acquisition and Conceptual Development, CUP, Cambridge.

Byram, M. (1989), Cultural Studies in Foreign Language Education, Multilingual Matters, Philadelphia.

Chomsky, N. (1975), Reflections on Language, Pantheon, New York.

Chowdhry, S., Sieler, K. and Alwis, L. (2014), "A study of the impact of technology-enhanced learning on student academic performance", Journal of Perspectives in Applied Academic Practice, Vol. 2 No. 3, pp. 3-15.

Choy, S.C. and Cheah, P.K. (2009), "Teacher perception of critical thinking among students and its influence on higher education", International Journal of Teaching and Learning in Higher Education, Vol. 20 No. 2, pp. 198-206.

Çifçi, T. (2016), "Effects of infographics on students achievement and attitude towards geography lessons", Journal of Education and Learning, Vol. 5 No. 1, pp. 154-166.

Cotter, E.M. and Tally, C.S. (2009), "Do critical thinking exercises improve critical thinking skills?", Educational Research Quarterly, Vol. 33 No. 2, pp. 3-14.

Duron, R., Limbach, B. and Waugh, W. (2006), "Critical thinking framework for any discipline", International Journal of Teaching and Learning in Higher Education, Vol. 17 No. 2, pp. 160-166.

Fadzil, H.M. (2018), "Designing infographics for the educational technology course: perspectives of preservice science teachers", Journal of Baltic Science Education, Vol. 17 No. 1, pp. 8-18, doi: 10. 33225/jbse/18.17.08. 
Hariss, J.L.H., Al-Bataineh, M.T. and Al-Bataineh, A. (2016), "One to one technology and its effect on student academic achievement and motivation”, Contemporary Educational Technology, Vol. 7 No. 4 , pp. 368-381.

Haugland, S. and Wright, J. (1997), Young Children and Technology: A World of Discovery, Allyn \& Bacon, New York.

Heer, J., Bostock, M. and Ogievetsky, V. (2010), “A tour through the visualization zoo", Communications of the ACM, Vol. 53 No. 6, pp. 59-67, doi: 10.1145/1743546.1743567.

Herold, B. (2016), Technology in Education: an Overview, Education Week, available at: http://www. edweek.org/ew/issues/ (accessed 02 January 2019).

Khan, I. (2011), "Learning difficulties in English: diagnosis and pedagogy in Saudi Arabia", Educational Research, Vol. 2, pp. 1248-1257.

Khan, I.A. (2014a), "Effectiveness of blended learning for teaching of English: an exploratory study", Research Journal of Recent Sciences, Vol. 3 No. 3, pp. 78-85.

Khan, I.A. (2014b), "Teachers perception towards significance of local culture in Foreign language learning", Journal of English Language, Vol. 1 No. 3, pp. 65-71.

Khan, I.A. (2016a), "Local culture in the foreign language classrooms: an exploratory study of teacher's preparedness in Saudi Arabia”, International Journal of Sciences: Basic and Applied Research, Vol. 25 No. 1, pp. 97-122.

Khan, I.A. (2016b), "Utilization of different technologies and media in learning writing skill in English: a case study", European Journal of Education Studies, Vol. 2 No. 6, pp. 143-156.

Khan, I.A. (2016c), "Positive attitude and English language learning: psycho-pedagogic connections", Arab World English Journal, Vol. 7 No. 1, doi: 10.2139/ssrn.2804020, available at: https://ssrn. com/abstract $=2804020$.

Khan, I.A. (2018), "Integration of local culture for the teaching of English through technology”, in Khan, I.A. (Ed.), Education, Technology and Pedagogy, Lambert Academic publishing, Mauritius, pp. 49-80.

Kramsch, C. (2001), Language and Culture, Oxford University Press, Oxford.

Krum, R. (2014), Cool Infographics: Effective Communication with Data Visualization and Design, John Wiley \& Sons, Indianapolis, Indiana.

Labbo, L.D., Sprague, L., Montero, M.K. and Font, G. (2000), "Connecting a computer center to themes, literature, and kindergartners' literacy needs", Reading Online, Vol. 4 No. 1, available at: http:// www.readingonline.org/electronic/labbo/ (accessed 06 August 2000).

Lamb, A. and Johnson, L. (2014), "Infographics part 1: invitations to inquiry", Teacher Librarian, Vol. 41 No. 4, pp. 54-58.

Leu, D. (2002), "The new literacies: research on reading instruction with the Internet and other digital technologies", in Farstrup, A.E. and Sameuls, S.J. (Eds), What Research Has to Say about Reading Instruction, 3rd ed., Newark, DE: International Reading Association, pp. 310-336.

MacQuarrie, A. (2012), Infographics in Education, Think Tank, available at: http://blog.k12.com/ infographics-education (accessed 10 July 2012).

McKnight, K., O’Malley, K.J., Ruzic, R., Horsley, M.K., Franey, J.J. and Bassett, K. (2016). Teaching in a digital age: how educators use technology to improve student learning, Journal of Research on Technology in Education, Vol. 48 No. 3, pp. 194-211, doi: 10.1080/15391523.2016.1175856.

Newsom, D. and Haynes, J. (2004), Public Relations Writing: Form and Style, 7th ed., Wadsworth Publishing, Belmont, CA.

Olsen, A.K. and Chernobilsky, E. (2016), "The effects of technology on academic motivation and achievement in a middle school mathematics classroom", NERA Conference Proceedings 2016, Vol. 2, available at: https://opencommons.uconn.edu/nera-2016/2.

O'Brien, M.G. (2017), "Literature review on the impact of second-language learning", Second Languages and Intercultural Council of the Alberta Teachers' Association and the Canadian Association of Second Language Teachers. SLIC-21 Impact of Second Language Learning.pdf. 
Peterson, E. and Coltrane, B. (2003), "Culture in second language teaching", CAL Digest, Vol. 3 No. 9, pp. 1-6.

Piaget, J. (1970), "Piaget's theory", in Mussen, P.H. (Ed.), Professional Psychology, Vol. 3 No. 1, pp. 703-832, 83, 85-86, doi: 10.1037/h0021507.

Piaget, J. (1985), The Equilibration of Cognitive Structures, University of Chicago press, Chicago,IL, p. 4.

Rezaei, N. and Sayadian, S. (2015), "The impact of infographics on Iranian EFL learners' grammar learning", Journal of Applied Linguistics and Language Research, Vol. 2 No. 1, pp. 78-85.

Savich, C. (2008), Improving Critical Thinking Skills in History, available at: http://www.eric.ed.gov/ ERICWebPortal/contentdelivery/servlet/ERICServlet?accno=ED501311 (accessed 05 May 2010).

Smiciklas, M. (2012), The Power of Infographics: Using Pictures to Communicate and Connect with Your Audiences, Pearson Education, Indianapolis.

Sylvester, J.J. (1858), "Note on the algebraical theory of derivative points of curves of the third degree", Philosophical Magazine, Vol. 16, pp. 116-119.

Vanichvasin, P. (2013), "Enhancing the quality of learning through the use of infographics as visual communication tool and learning tool", the Proceedings ICQA 2013: The International Conference on QA Culture: Cooperation or Competition. Bangkok: Offset Plus, pp. 135-142, available at: http://www.icqa2014.com/downloads/Proceeding_29.pdf (accssed 13 December 2014).

Vygotsky, L.S. (1978), Mind in Society: the Development of Higher Psychological Processes, Harvard University Press, Cambridge, MA, p. 86.

Wantulok, T. (2015), How Important Is Technology in Education, available at: https://marketing.pinecc. $\mathrm{com} / \mathrm{blog} /$ the-importance-of-technology-in-education-pine-coves-top-10-reasons (accessed 04 April 2019).

Warren, W., Memory, D. and Bolinger, K. (2004), "Improving critical thinking skills in the United States survey course: an activity for teaching the Vietnam war", History Teacher, Vol. 37 No. 2 , pp. 193-209.

\section{Further reading}

Huseyin, B. (2017), "The psychological impact of infographics in education", Broad Research in Artificial Intelligence and Neuroscience, Vol. 8 No. 4, p. 101.
Infographics

on English language teaching 


\section{Appendix}

Questionnaire for teachers $(N=40)$

(Adapted from Bicen and Beheshti, 2017)

Name (optional):

Experience: years

Any training in technology integration: Yes/No

\begin{tabular}{|c|c|}
\hline S.N. & Statement \\
\hline 1 & Infographics are important tools. \\
\hline 2 & I like infographics and share on my social media pages. \\
\hline 3 & I can create simple and instructional infographics if I have software. \\
\hline 4 & $\begin{array}{l}\text { Infographics can be helpful in presenting subjects in an effective and summarized } \\
\text { manner. }\end{array}$ \\
\hline 5 & Infographics motivates students to learn more. \\
\hline 6 & If Infographics are nicely used in the class, learning will be more effective. \\
\hline 7 & Infographics can enhance the imagination for cognition. \\
\hline 8 & Infographics can also develop critical thinking and creativity. \\
\hline 9 & Infographics enable the students to learn complex content in easy way. \\
\hline 10 & Infographics improve understanding of the subject. \\
\hline 11 & Infographics enhance communication skills. \\
\hline 12 & Infographics create visual impact for better learning. \\
\hline 13 & Infographics are effective tools for showing information in systematic ways. \\
\hline 14 & Infographics also createmeaningful visual design and tools. \\
\hline 15 & Infographics are not effective for teaching/learning English. \\
\hline 16 & Any other perceptions which you want to share: \\
\hline
\end{tabular}

\section{Corresponding author}

Intakhab Alam Khan can be contacted at: ikhan1@kau.edu.sa

For instructions on how to order reprints of this article, please visit our website: www.emeraldgrouppublishing.com/licensing/reprints.htm Or contact us for further details: permissions@emeraldinsight.com 